\title{
El artículo 14 de las Reglas de Procedimiento del M. P. Mitis ludex. Supuestos de hecho y causas de nulidad
}

\author{
On Article 14 of the Rules of Procedure of Motu Proprio \\ Mitis ludex: Facts and Grounds of Marriage Nullity
}

\section{Juan Ignacio BAÑARES}

Profesor Ordinario de Derecho Matrimonial Canónico Universidad de Navarra. Facultad de Derecho Canónico orcid 0000-0002-9886-2471

jibanares@unav.es
Resumen: El papa Francisco promulgó unas nuevas normas para los procesos matrimoniales a través del M. P. Mitis ludex y de las Reglas de Procedimiento anexas. Los nuevos cánones 1683-1687 del Código abrían la posibilidad de un proceso brevior ante el Obispo para algunas causas de nulidad referidas a defecto o vicio del consentimiento, siempre que existan unas determinadas condiciones. El artículo 14 de las Reglas de Procedimiento incluía un elenco de supuestos de hecho en los que podrían existir esas condiciones. Y un posterior Subsidio Aplicativo del Decano de la Rota Romana a los obispos desarrollaba algo más este punto. El presente texto parte del ius connubii que da sentido a todo ordenamiento jurídico del matrimonio, y analiza cada uno de los supuestos de hecho recogidos en el art. 14 de las Reglas desde el punto de vista sustantivo: el bien jurídico que protege la causa de nulidad correspondiente y los criterios para medir la gravedad de la lesión que puede producirse en cada caso.

Palabras clave: Reglas de procedimiento del M. P. Mitis ludex, Proceso breve de nulidad ante el obispo, Consentimiento y nulidad matrimonial.
Abstract: Pope Francis promulgated new regulations for the marriage nullity process in M. P. Mitis ludex and the Rules of Procedure in the appendix. The new canons 1683-1687 in the Code foresee the possibility of a brevior process before the bishop in relation to certain grounds for nullity relating to defects in matrimonial consent, under certain conditions. Article 14 of the Rules of Procedure includes a list of cases in which these conditions may be present. In addition, a later Subsidium Applicativum of the Dean of the Rota Romana further elaborates on this point. The present text is based on the ius connubii that informs the legal order of marriage as a whole. Furthermore, it offers an analysis of each of the cases referred to in Article 14 of the Rules from a substantive viewpoint: namely, the good safeguarded by the corresponding ground for nullity and the criteria to assess the degree of harm that may be done in each case.

Keywords: Rules of Procedure of Motu Proprio Mitis ludex, Marriage Nullity and Matrimonial Consent, The brevior Process of Nullity before the Bishop. 


\section{INTRODUCCIÓN}

omo es sabido, la aparición de algunos supuestos de hecho como ejemplos de casos en los que podría caber el proceso brevior de nulidad del matrimonio -que en realidad, aunque se dividen en ocho apartados, son más de ocho, puesto que algunos de ellos abarcan situaciones diferentes- ha dado lugar a diversas intervenciones, a veces apasionadas, y a la aparición en escena de nuevas ilusiones y esperanzas, y también de críticas y miedos. A todo ello nos referiremos más adelante.

Nos conviene advertir la perspectiva desde la que hemos considerado esos supuestos del artículo 14 de las Reglas de Procedimiento (RP). Por una parte, el objeto directo de nuestro análisis es el contenido de dicho artículo -y sus implicaciones, interpretaciones y consecuencias-, no el texto general del Motu Proprio (MP). Por otra, la perspectiva formal, aun refiriéndose a normas procesales, arranca de criterios del derecho sustantivo: de la determinación del bien jurídico que protege cada capítulo de nulidad matrimonial. En realidad, no se trata tanto de consideraciones teóricas sobre los supuestos, sino de estudiarlos desde su relación con una posible causa de nulidad: o sea, de estudiar en primer lugar los capítulos de nulidad existentes, y en segundo lugar la relación, identidad o inclusión que puede tener cada supuesto. Por este motivo, el esfuerzo central está dirigido a analizar las condiciones o requisitos que deben darse en todos o en cada uno de estos supuestos. Todo ello en función de su naturaleza jurídica, del contenido concreto de cada uno, de la relación con uno o varios capítulos de nulidad y de los elementos que consideramos esenciales para la prueba. Finalmente haremos referencia a las dudas, riesgos y medios que se han planteado o pueden plantearse a propósito de la aplicación de estas nuevas normas.

\section{El DERECHO AL MATRIMONIO Y EL DERECHO DEL MATRIMONIO}

Desde hace años, pero tal vez ahora con más convicción, al pensar en el derecho matrimonial considero que lo primero es la persona, su peculiar modo de ser femenino o masculino, que da pie a la complementariedad precisamente porque la sexualidad humana es vivida desde un sujeto que es persona ${ }^{1}$. Esta

${ }^{1}$ Vid. J. Hervada - P. Lombardía, El Derecho del Pueblo de Dios. Hacia un sistema de Derecho Canónico, III Derecho Matrimonial (1), Eunsa, Pamplona 1973; y J. Hervada, Una Caro. Escritos sobre el matrimonio, Eunsa, Pamplona 2000; cfr. también C. J. ERRÁZURIZ M., Il matrimonio e la famiglia quale bene giuridico ecclesiale, Pontificia Università della Santa Croce, Facoltá di diritto Cano- 
diversidad e igualdad constitutiva y la tendencia a la unión amorosa de mujer y varón de por sí apuntan a un tipo de relación intersubjetiva cuyo contenido no es inventado por ellos, sino ofrecido por su propia estructura ontológica. A la vez, la unión firme, abierta y exclusiva a la que tiende el amor personal de varón y mujer basado en la complementariedad de ambos, implica la constitución de un nuevo rasgo del ser -la conyugalidad- que nace de una relación de justicia que sólo puede ser establecida desde el ámbito de la posesión de sí y de una adecuada libertad. Por esta razón el derecho al matrimonio -el ius connubii - no tiene su origen en el ordenamiento jurídico, sino que él mismo es originario y nativo, y fundamento del ordenamiento positivo. Lo que no está fundado en él o no tiende a hacer posible su ejercicio y su conveniente protección, no tiene sentido en un ordenamiento matrimonial: y esto tanto por lo que se refiere a la definición del matrimonio y sus propiedades, como a la regulación de los impedimentos, la forma o el consentimiento, que constituyen sus tres pilares básicos.

Desde esta exigencia de justicia que surge de la misma realidad personal del ser humano se explica todo el desarrollo normativo. Y por su propia naturaleza esta exigencia de justicia protege fundamentalmente dos principios: el principio de la verdad acerca del matrimonio mismo y el principio de la libertad de los contrayentes. A estos dos se debe añadir un corolario importante: el principio formal, porque el matrimonio es social y es sociedad, porque la dimensión de justicia siempre es intersubjetiva y necesita de la función y perspectiva de un tercero, porque la sociedad tiene derecho a conocer los sujetos de una realidad que la conforma a ella misma a través de las relaciones de conyugalidad y demás formas de parentesco. Por lo demás, el derecho al matrimonio debe ser protegido y respetado antes, durante y después del matrimonio. La persona humana exige igualmente el reconocimiento de esa particular unión de amor que implica una mutua coposesión en orden a la complementariedad de la que nace, como la protección del vínculo que da origen a esa unión, una vez contraído. De ahí que la defensa del ius connubii no consista en favorecer en todo caso una posibilidad de contraer, sino de facilitar el ejercicio del derecho cuando está expedito y salvaguardar el derecho -las características del vínculo conyugal- cuando ha sido rectamente establecido por las partes.

nico, Roma 2016, especialmente el capítulo Persona e natura nel matrimonio: la dimensione di giustizia, 215-234. 


\section{HeCHOS, DERECHO Y PROCESO DE NULIDAD}

A propósito de los capítulos de nulidad matrimonial, tal vez conviene recordar que una cosa es la nulidad del pacto conyugal; otra cosa distinta es el capítulo de nulidad concreto que ha impedido la constitución del vínculo (con su fundamento en el derecho y su manifestación en diversos hechos); un tercer elemento son los medios con los que pueda ser probada externamente la eventual nulidad; y una última cuestión -ciertamente vinculada a la anterior pero no determinada por ella- estriba en que se alcance o no la certeza moral por parte del tribunal.

Como es lógico, la reforma del Mitis Iudex (MI) y las consiguientes Reglas de Procedimiento (RP) se refieren al plano del derecho en relación con el reconocimiento o no de un vínculo conyugal constituido. La existencia de la nulidad en sí misma, es objetiva y por tanto pertenece al ámbito de la realidad: el problema es el conocimiento adecuado de ella. Se trata de un hecho que encierra una dimensión de justicia: que presenta una exigencia de reconocimiento de lo debido a alguien. Por ser precisamente una realidad jurídica que se constituye a partir de una dimensión permanente de la persona -su modo de ser persona, femenino o masculino-, el derecho positivo no tiene facultad ni fuerza para modificarla. Todo lo que busca el proceso es precisamente descubrir la realidad y -en su caso- probar y fallar la nulidad o declarar la validez. El fundamento de la verdad -de lo conocido como verdad- es la realidad misma, que es la que mide la adecuación del intelecto a la cosa. Y ése constituye por tanto el objetivo del proceso.

En segundo lugar debemos considerar que la voluntad consensual de los contrayentes es de por sí causa eficiente -y suficiente- para la génesis del vínculo conyugal. Sin embargo, aun siendo el único elemento con capacidad de «causar», el ordenamiento jurídico exige la existencia de unas condiciones de los contrayentes y de una forma de expresión y recepción del consentimiento, de modo que pueda ser testimoniado, y por tanto recibido -y registrado y protegido- por la sociedad.

Las condiciones objetivas que -conforme a derecho- impedirían que la voluntad matrimonial de los cónyuges -adecuadamente manifestada- diera origen a un vínculo matrimonial se llaman impedimentos. Debido a que restringen el derecho fundamental a contraer matrimonio, sólo puede establecerlos la máxima autoridad y deben ser interpretados restrictivamente. Como es sabido, hay algunos que están basados en el derecho divino natural (con un 
arraigo en él más o menos directo e inmediato) y otros derivan del derecho positivo, y están referidos a algunos bienes de carácter sobrenatural (o, en algunos casos, natural) que la Iglesia considera necesario proteger mediante una ley de carácter irritante.

Supuestas las condiciones objetivas de los contrayentes ${ }^{2}$, éstos pueden producir un acto de consentimiento por el que varón y mujer se dan y aceptan mutuamente como esposo y esposa expresándolo conforme a derecho: es decir, de acuerdo con la forma canónica que la Iglesia exige como condición de validez para que puedan contraer matrimonio los bautizados o recibidos en ella ${ }^{3}$.

Hasta ahora, para discernir a través de un proceso la validez o no de un matrimonio contraído, en ciertos casos relativos a algún impedimento o al defecto de forma cabía un proceso abreviado. Abreviado, se entiende, no porque no tuviera el objetivo general de todo proceso de nulidad (la averiguación de la verdad desde el inicio), o porque no permitiera la defensa de las partes implicadas y del defensor del vínculo, o porque exigiera menos pruebas o menor certeza moral por parte de los jueces del tribunal eclesiástico..., sino precisamente porque al tratarse de elementos objetivos cabía que en algunos supuestos un documento de particular fiabilidad bastara para dejar claramente probada la nulidad del vínculo aparentemente contraído. Se llamaba proceso documental y exigía la prueba documental inmediata y plena en casos de ciertos impedimentos o de defecto sustancial de forma.

¿Por qué no se podía aplicar un proceso similar cuando el capítulo de nulidad provenía del propio defecto o vicio del consentimiento de uno o ambos cónyuges?

\section{LA PECULIARIDAD DEL CONSENTIMIENTO MATRIMONIAL}

En efecto, a partir de aquellas condiciones objetivas de los sujetos y de la forma empleada, lo capital es el acto de consentimiento por el que los contrayentes manifiestan mutuamente la entrega y aceptación de sí mismos en cuanto mujer y varón. Como este acto de entrega sólo puede ser realizado desde lo íntimo de la libertad personal, sin él no habría posibilidad de que surgiera el vínculo conyugal.

\footnotetext{
2 Es decir, las referidas a los impedimentos de los que acabamos de hablar.

3 Cfr. Intervención de Mons. F. L. Ladaria en la Presentación del M. P. «Mitis Iudex Dominus fesus» (15-VIII-2015), realizada el 8-IX-2015, 11 (texto accesible en http://www.vatican.va).
} 
Como es obvio los capítulos de nulidad referidos al consentimiento dicen referencia a la autenticidad de la relación entre el acto de voluntad de los contrayentes y la voluntad verdaderamente matrimonial que exige el pacto. Es necesario, por tanto: a) que los contrayentes, por la misma constitución del sujeto, tengan el suficiente señorío de sí como para poder donarse (y recibir al otro) como cónyuge; b) que este dominio de sí no haya sido seriamente lesionado por la intervención manipulante de un tercero, a través de la violencia directa, de la creación de un miedo grave o de la producción efectiva de ciertos engaños directamente relacionados con el consentimiento matrimonial y con alguna cualidad del otro contrayente de especial relevancia en el consorcio de vida conyugal; c) que haya un conocimiento suficiente de la sustancia del matrimonio y de la persona del otro contrayente, de manera que la aportación del intelecto permita que el acto de voluntad quiera lo que es el matrimonio y al otro como cónyuge; d) que además la voluntad de ambos contrayentes acepte y done realmente -es decir, desde el mismo acto interior- la conyugalidad entre mujer y varón; e) que no se excluya expresamente alguna propiedad o elemento esencial, es decir, cuya presencia es imprescindible para la donación y aceptación conyugal plena y mutua; y f) que la voluntad no esté vinculada expresamente a la realización de un supuesto determinado -de pasado o de presente- desconocido por el contrayente en el momento de emitir el consentimiento.

Estos supuestos dan lugar -con sus condiciones particulares-a los diversos capítulos de nulidad por incapacidad (c. 1095); por violencia, miedo (c. 1103) o dolo (c. 1098); por ignorancia o error acerca de la sustancia del matrimonio, o error que determina la voluntad (cc. 1096; 1099); por error acerca de la persona misma o de una cualidad directa y principalmente pretendida (c. 1097) o por condición de presente o de pasado (c. 1102); o por simulación o exclusión del matrimonio mismo o de uno de sus elementos o propiedades esenciales (c. 1101).

Los hechos que pueden desencadenar la aparición de alguno de estos capítulos de nulidad pueden ser muy variados, pero en lo que se refiere al consentimiento la simple yuxtaposición de hechos no puede producir la nulidad por sí misma: pueden interferir como causa subjetiva que motiva un acto de voluntad insuficiente o viciado, o bien (p. e. en el caso de la brevedad de la convivencia conyugal, o del aborto provocado), puede manifestar -en el in facto esse- un síntoma de una causa de nulidad que lógicamente tuvo lugar en el in fieri. 
Como siempre en los procesos de nulidad, de lo que se trata es de descubrir la existencia o no de la posible causa de nulidad y de poder alcanzar una certeza moral a través de hechos probados. Lo que trata de favorecer el MI es la celeridad de la sentencia cuando, también en el caso de ausencia o defecto de consentimiento, la nulidad pueda ser probada de modo inmediato debido a la claridad e irreversibilidad de los hechos que se aducen. De ahí que el nuevo canon 1684 en estos casos exija que el libelo de demanda incluya: a) los hechos sobre los que se funda la demanda misma, de modo breve, íntegro y claro; b) las pruebas que puedan ser inmediatamente recogidas por el juez; y c) los documentos pertinentes ${ }^{4}$. La exigencia previa del acuerdo o consentimiento de las partes es una medida prudencial para evitar posibles lesiones, para no impedir el derecho al proceso ordinario si alguna de ellas lo prefiere o lo estima más oportuno -lo que viene a remarcar, sensu contrario, el carácter extraordinario del proceso brevior $-\mathrm{y}$ también porque si una parte se opusiera podrían caber más dudas acerca de los hechos aducidos o de las pruebas presentadas.

Importa recordar que no se trata de un pre-juicio que determine la sentencia, sino de un primer juicio acerca de la evidencia que aparece entre lo que se propone como prueba y la cualidad y veracidad de lo probado: es decir, entre lo que se argumenta acompañado de documentación sólida y de la lesión del bien jurídico que protege un determinado capítulo de nulidad matrimonial.

$\mathrm{Al}$ tratar acerca del MI se han destacado -como es normal- los cambios introducidos: especialmente la no necesidad de la doble sentencia conforme, el subrayado de la responsabilidad de la función judicial del obispo en las causas matrimoniales y -como desarrollo de este subrayado- la intervención directa del obispo como juez en el proceso brevior. A la vez, no hay que olvidar que el MI exige el respeto y el cuidado de cuatro principios clave en la actuación procesal en las causas de nulidad matrimonial: a) respeto a la verdad, al realismo jurídico o -lo que es igual- a la dimensión objetiva de justicia en las relaciones intersubjetivas y en concreto a la estabilidad y permanencia del vínculo una vez constituido rectamente por el pacto conyugal entre los contrayentes; b) respeto a la naturaleza auténticamente judicial, como mejor garantía de la búsqueda de la verdad in casu en tema tan importante, delicado y complejo como las causas matrimoniales; y también para evitar expresamente una posible «vía administrativa» que resultaría menos apta -si no insuficiente- para la defensa del respeto a la ver-

${ }^{4}$ Cfr. F. Heredia, El proceso más breve ante el Obispo, Anuario de Derecho Canónico 5 Supl. [Octubre 2016], 97-122; especialmente 108-111. 
dad y para la posibilidad -en su caso- de auténtica defensa de la parte demandada; c) respeto al carácter riguroso, inmediatamente evidente y fiable de las pruebas; y d) por último, respeto a un concepto claro y un itinerario convincente de la certeza moral por parte del juez. Estos principios no sólo siguen vigentes -también para el proceso brevior- sino que el legislador los explicita y enfatiza ${ }^{5}$.

Así pues, por lo que se refiere a la reforma introducida por el MI en general y al proceso brevior en particular, se puede afirmar que los objetivos principales que persiguen los principios indicados son dos: facilitar la celeridad del desarrollo de la causa en esos supuestos particulares que parecen permitirlo sin detrimento del respeto a los principios, y encuadrar todo el proceso en el contexto de una pastoral directa de acompañamiento a los fieles ${ }^{6}$.

Antes nos hemos referido a las posibles causas de nulidad debidas a ausencia o defecto del consentimiento matrimonial. Debemos pasar ahora a contemplar los ejemplos fácticos que sugiere el art. 14 de las RP en relación con la posibilidad de utilización del proceso brevior en vez del proceso ordinario. De esa relación, se pueden hacer determinadas consideraciones, que han sido ya apuntadas y que vamos a recoger brevemente.

\section{LAS NORMAS DEL ARTíCULO 14 DE LAS NUEVAS REGLAS DE Procedimiento}

En primer lugar, el propio artículo 14, 1 se inicia indicando que se trata de «circunstancias que pueden consentir tratar la causa de nulidad matrimonial por medio del proceso más breve según los cánones 1683-1687». Tal es, por tanto, su naturaleza: circunstancias, hechos; no, derecho.

\footnotetext{
${ }^{5}$ Refiriéndose en concreto al papel del Defensor del vínculo, en la Presentación del M. P. uno de los secretarios de la Comisión especial que preparó el texto promulgado afirmaba sin ambages: «Il Difensore del vincolo difende il diritto delle parti, di non essere ingannate con una sentenza di nullità che stia in contrasto con l'esistenza di un vero matrimonio. Tale ingiusta dichiarazione di nullità matrimoniale non troverebbe alcun legittimo avallo nel ricorso alla carità o alla misericordia. Queste, infatti, non possono prescindere dalle esigenze della verità. Sia il Difensore del vincolo che le stesse parti nonché i testimoni sono esortati ed obbligati ad agire con pieno rispetto alla verità». (Mons. N. SCHÖch, Presentación del M. P. «Mitis Iudex Dominus fesus», cit., 13).

${ }^{6}$ Sobre los aspectos más técnicos del proceso brevior, puede consultarse P. MONETA, La dinamica processuale nel m. p. «Mitis Iudex», Ius Ecclesiae 28 (1) 2016, 39-62, especialmente 46-61; C. M. MORÁN BUSTOS, El proceso «brevior» ante el obispo diocesano: requisitos procesales y sustantivos de un proceso que ha de ser extraordinario, Revista General de Derecho Canónico y Eclesiástico del Estado 41 (2016) en http://www.iustel.com; IDEM, Retos de la reforma procesal de la nulidad del matrimonio, Ius Canonicum 56 (2016) 9-40; G. NúÑEZ, El proceso brevior: exigencias y estructura, Ius Canonicum 56 (2016) 135-155.
} 
En segundo lugar la norma da comienzo a la enumeración diciendo que entre estas circunstancias «se encuentran por ejemplo»...; y termina con un «etcétera», que obviamente significa que pueden existir otras análogas y que no se trata de un listado cerrado. Esta consideración abunda en lo señalado: estamos hablando de hechos. Por otro lado, ni por el tipo de norma ni por el modo de expresarlo se puede suponer una voluntad normativa de crear nuevos capítulos de nulidad.

En tercer lugar ha sorprendido a la doctrina la variedad de la enumeración: no porque los supuestos no puedan ser diferentes -en su número-, sino porque se mezclan casos de diversa naturaleza. En efecto, pese a lo que acabamos de indicar a propósito de la naturaleza fáctica de los supuestos, hay que especificar que se incluyen tres casos que dicen relación directa a un capítulo de nulidad concreto: «la ocultación dolosa de la esterilidad o de una grave enfermedad contagiosa o de hijos nacidos en una relación precedente o de un encarcelamiento, (...) la violencia física ejercida para arrancar el consentimiento, [y] la falta de uso de razón comprobada por documentos médicos». Evidentemente tampoco aquí se trata de establecer nuevos títulos de nulidad, sino que se recogen algunos de los referidos a la ausencia o vicio del consentimiento.

De hecho, el Subsidio Aplicativo (SA) de enero de 2016 recalca: a) que la enumeración del artículo 14 de las RP contiene «circunstancias, enumeradas de modo ejemplificativo» (SA, 3, 1, a, $2^{\circ}$ ); b) que «se trata, simplemente, de situaciones que la jurisprudencia, desde hace tiempo, ha enumerado como elementos sintomáticos de invalidez del consentimiento nupcial, los cuales pueden ser fácilmente comprobados por testimonios o documentos de inmediata adquisición» (SA, 3, 1, b).

En definitiva, la enumeración del artículo 14 de las RP recoge, por una parte, algunos capítulos de nulidad que en ciertos casos pueden tener una prueba más directa e inmediata. Por otra parte, indica algunos supuestos de hecho que en la jurisprudencia se han presentado con más frecuencia vinculados a un determinado capítulo de nulidad y que también podrían en ciertos casos ser probados de modo claro y rápido por datos que fundamenten directamente la certeza del juez; obviamente eso no significa que basten por sí mismos como prueba plena.

Por tanto, lo común en todos los supuestos de la enumeración es la posibilidad de la existencia de un capítulo de nulidad referido al consentimiento -ausencia o vicio- que in casu y prima facie, parece presentarse con pruebas especialmente relevantes, inmediatas y sencillas. El SA señala expresamente que 
en estos casos son las circunstancias de personas o de hechos las que hacen «manifiesta» la nulidad y que normalmente aparecerán con motivo de una «investigación prejudicial o pastoral precedente» $\left(\mathrm{SA}, 3,1, \mathrm{a}, 2^{\circ}\right)$. No olvidemos que al tratar del elenco enumerado en este artículo 14 no estamos hablando de capítulos de nulidad, sino de circunstancias que hacen posible el acceso al proceso brevior: sólo la sentencia establece la aplicación pertinente del derecho a los hechos. Pero pasemos a contemplar siquiera brevemente cada uno de los distintos supuestos?

\subsection{La falta de fe que puede generar la simulación del consentimiento o el error que determina la voluntad}

Desde el primer momento -antes del SA- la gran mayoría de autores comprendió y señaló que las nuevas normas no estaban pretendiendo establecer la falta de fe subjetiva de los contrayentes como un nuevo capítulo de nulidad. La falta de fe -como hecho en sí- no lesiona gravemente ninguno de los bienes jurídicos esenciales del matrimonio, cuya sustancia, características esenciales y fines reside en la propia estructura de la persona humana ${ }^{8}$.

El SA habla de un falso conocimiento del matrimonio que podría llegar a determinar la voluntad (c. 1099), o una «percepción del matrimonio como una mera forma de gratificación afectiva que puede inducir a los contrayentes a la simulación del consentimiento, es decir, a la reserva mental sobre la misma permanencia de la unión, o su exclusividad» (SA 3, 1, c).

Respecto al error que determina la voluntad, no parece fácil que sea producido directamente por la falta de fe: cada vez los matrimonios que se contraen en la Iglesia -en España, me refiero- son menos en número; eso significa que hay menos gente que accede al matrimonio y se usan diferentes modos de vivir en pareja, o bien que accede al matrimonio civil porque rechaza ex-

\footnotetext{
${ }^{7}$ Cfr., p. e., M. D. Cebriá García, Las circunstancias y bechos orientativos de la nulidad clara del art. 14 del Motu Proprio Mitis Iudex Dominus Iesus, para abrir el proceso breve ante el Obispo, Revista General de Derecho Canónico y Derecho Eclesiástico del Estado 40 (2016); en la página 8 se hace referencia a algunos equívocos y malentendidos.

${ }^{8}$ En una Presentación del nuevo proceso matrimonial, en la 110 Asamblea Plenaria de la Conferencia Episcopal Argentina, uno de los secretarios de la Comisión especial, Mons. A. BungE recordaba «La causa de la nulidad no es la falta de fe en cuanto tal. Ésta sólo constituye la circunstancia que, en el caso particular, lleva a una o ambas partes a excluir algún elemento o propiedad esencial del matrimonio, o a errar sobre ellos, de modo tal que dicho error afecta su voluntad que lo mueve a prestar el consentimiento» (PDF, http://www.awbunge.com.ar/, p. 17), consultado el 20 de octubre de 2016.
} 
presamente el contraído ante la Iglesia o porque las normas canónicas no lo permiten en su caso. Por otro lado, la presión familiar o social en este tema no es comparable con la que pudiera haber hace unos decenios. Aunque actualmente haya menos práctica religiosa y menor formación, sin embargo tal vez la elección del matrimonio en la Iglesia puede ser más fruto de una decisión personal de quienes contraen y con cierta conciencia por lo menos de lo que la Iglesia entiende por matrimonio, quizá precisamente porque su propia idea no coincide ${ }^{9}$. Es difícil, en efecto, que los contrayentes, durante el proceso de petición de matrimonio ante la Iglesia y el cumplimiento de las normas establecidas, puedan mantener un error acerca del matrimonio y/o sus elementos esenciales ${ }^{10}$. Y más difícil parece que tal error pudiera ser probado directa e incontestablemente por testimonios o pruebas. No olvidemos que estas circunstancias no se pueden considerar como presunciones in casu, y mucho menos como presunciones iuris et de iure. Lo que hay que probar no es la falta de fe, o la opinión contraria al matrimonio tal como es en sí, sino que se lesiona el bien jurídico protegido: en este caso, la verdad de la voluntad de conyugarse ${ }^{11}$.

9 Vid. J. FERRER ORTIZ, Valoración de las circunstancias que pueden dar lugar al proceso abreviado, Ius Canonicum 56 (2016) 157-192. Refiriéndose a España el autor señala algunos factores estadísticos que muestran los cambios sociales de los últimos decenios, y concluye que esos signos «permiten pensar que no va a ser tan frecuente que la falta de fe lleve a la nulidad del matrimonio canónico, ni por exclusión de un elemento o propiedad esencial, y menos todavía por exclusión del matrimonio mismo o por un error determinante de la voluntad» (ibid., 175).

10 Vid. P. MAJER, El error que determina la voluntad (can. 1099 del CIC de 1983), Eunsa, Pamplona 1997; M. GAS AIXENDRI, Error determinante de la voluntad (c. 1099 CIC) y simulación (c. 1101 \$ 2 CIC). Criterios de delimitación y prueba, con especial referencia a la sacramentalidad del matrimonio, Revista General de Derecho Canónico y Derecho Eclesiástico del Estado 18 (2008) en http: //www.iustel.com.

${ }^{11}$ Discurso de Francisco a la Rota Romana, 22-I-2016. Precisamente al comentar la posibilidad de una simulación o un error determinante de la voluntad eventualmente derivada de una ausencia de fe, afirmaba el Romano Pontífice: «Es bueno recordar con claridad que la calidad de la fe no es una condición esencial del consentimiento matrimonial, el cual, de acuerdo con la doctrina de siempre, puede ser minado solamente a nivel natural (cfr. CIC, can. $1055 \$ \$ 1$ e 2)» (//w2.vatican.va/content/francesco/es/speeches/2016/january/documents/papa-francesco_20160122_anno-giudiziario-rota-romana.html). Por lo demás, en mi opinión el error pervicax es distinto del error determinante; se trata de una condición necesaria, pero no suficiente, para que la voluntad pueda ser determinada por él, puesto que es compatible con el conocimiento -no aceptado- de la doctrina sobre el matrimonio y en ese caso -si se mantuviera ya conscientemente- pasaría a convertirse en causa simulandi (cfr. J. I. BAÑARES, La relación intelecto-voluntad en el consentimiento matrimonial: notas sobre los cc. 1096-1102 del CIC de 1983, 66 [1993] 553-603, especialmente 567576). Finalmente, hay que considerar seriamente la falta de fe -al menos en la sacramentalidadde muchos cristianos no católicos a los que sin embargo nadie niega el ius connubii para contraer matrimonio (que la Iglesia reconoce incluso como sacramental, si se trata de cristianos de otras confesiones religiosas, siempre que no haya dudas acerca de la validez del bautismo). 
En casos más enconados, si la voluntad de las partes al contraer se basa en una idea gravemente equivocada del vínculo conyugal y/o de sus elementos esenciales, lo más probable es que tal error transite hacia una causa simulandi: que le lleve a querer expresamente algo incompatible con el matrimonio tal como es, aunque sepa lo que propone la Iglesia. Parece que en el momento en que el intelecto del contrayente es consciente de la contradicción objetiva entre lo que pretende él y lo que propone la Iglesia, en ese momento ya no puede hablarse de error determinante de la voluntad, justamente porque si a partir de entonces mantiene su idea de matrimonio será ya a través de una exclusión consciente: del matrimonio mismo o de alguno de sus elementos esenciales.

En efecto, la explicación que sugiere el SA sobre la forma en que puede actuar la falta de fe, viene más bien de la «crisis de conocimiento iluminado por la fe» ${ }^{12}$, del «influjo de la mentalidad mundana», del «subjetivismo», nociones generales que pueden llevar al contrayente a desear otro tipo de unión distinta del verdadero matrimonio, pero difícilmente cualquiera de las partes llegarán al momento del enlace matrimonial sin haber oído nada acerca del concepto de matrimonio que mantiene y propone la Iglesia. Desde este punto de vista el primer ámbito de influencia posible entre la falta de fe y la simulación tiene lugar en los supuestos en que la voluntad de al menos una de las partes rechaza el mismo vínculo conyugal: sea porque no quiere ningún compromiso, sea porque no desea darse y recibirse como persona femenina y masculina, o porque rechaza la conyugalidad de la unión, no quiere ser esposa o esposo, no admite un título de justicia en el compromiso mutuo, etc. Todas estas voluntades $-\mathrm{y}$ otras más- son equivalentes porque existe una ausencia querida de voluntad matrimonial, y sin un impulso propio de donación-aceptación, no puede surgir el vínculo; es más: se está queriendo otro tipo de relación incompatible con la verdad de las nupcias. Todos estos supuestos serían casos variados de una misma voluntad de simulación total, en cuanto que excluyen (no quieren, positivamente) el matrimonio, puesto que pretenden continuar sin vinculación alguna que pueda reconocerse en justicia (es decir, como algo otorgado y debido).

También puede darse, efectivamente, que la falta de fe -en el contexto cultural actual posmoderno y relativista- lleve a alguna de las partes a querer una unión matrimonial expresamente privada de algún elemento esencial, es-

${ }^{12}$ Discurso a la Rota Romana, 23-I-2015. 
pecialmente la permanencia del vínculo o la exclusividad de la relación propia de los esposos.

Indudablemente la falta de fe como causa subjetiva de una voluntad matrimonial ausente o insuficiente podría conducir también a otros capítulos de nulidad de índole muy diversa: por ejemplo, la exclusión de la prole, pero también el dolo, el miedo o la violencia. En cualquier caso, como se sabe, la causa motiva de la voluntad objetiva -sea voluntad matrimonial o sea contraria de cualquier modo- puede servir para explicar mejor el itinerario psicológico del acto de exclusión del contrayente, pero -obviamente- no se identifica ni puede identificarse con ese acto, que es el que verdaderamente causa la nulidad. Las causas psicológicas con frecuencia pueden ayudar, pero no son ni pueden sustituir al objeto del acto de voluntad: ni de contraer, ni de excluir. No es tan importante demostrar por qué quise o no casarme -o por qué quise una unión de tal manera o de tal otra-, sino más bien demostrar lo que realmente se quiso y -en su caso- la oposición esencial entre ese acto de voluntad y la estructura del matrimonio tal como es ${ }^{13}$.

El bien jurídico protegido en este supuesto es la verdad del matrimonio como objeto de la voluntad matrimonial de las partes: en consecuencia, afecta tanto a la verdad objetiva del matrimonio como a la voluntad subjetiva de los contrayentes. Por eso la prueba deberá recaer acerca del objeto de voluntad que tenían las partes en el momento del matrimonio, y la dificultad principal residirá en que pueda probarse directamente a partir de circunstancias de las personas y de los hechos, sostenidos por testimonios o documentos que hagan mani-

${ }^{13}$ Se pueden contrastar sobre el particular, M. ALENDA SALINAS, ¿Nuevas causas de nulidad matrimonial canónica? El sentido del art. 14, 1 de las Reglas de procedimiento contenidas en la Carta Apostólica Mitis Iudex Dominus Iesus, Revista General de Derecho Canónico y Derecho Eclesiástico del Estado 40 (2016) en http://www.iustel.com; M. F. POMPEDDA, Mancanza di fede e consenso matrimoniale, Studi di Diritto Matrimoniale Canonico, vol. I, Giuffrè, Milano 1993, 399-450, especialmente 418-419; T. RINCÓN PÉREZ, La exclusión de la sacramentalidad del matrimonio. ¿ Son convincentes las razones que inspiran el incipiente cambio jurisprudencial?, Ius Ecclesiae 6 (1994) 465-487; IDEM, La peculiaridad sacramental del matrimonio y sus consecuencias canónicas (Comentario a las Alocuciones del Papa a la Rota Romana de 2001 y 2003), Ius Canonicum 44 (2004) 281-307; D. Moreno RAMÍREZ, Relevancia de la sacramentalidad del matrimonio en relación con la nulidad del consentimiento, Madrid 2014 (se trata de una tesis doctoral con un encuadre algo particular, si bien absolutamente legítimo; puede interesar especialmente el recorrido histórico, aunque la bibliografía no es exhaustiva); A. D'AURIA, Fede e sacramentalità del matrimonio. La prospettiva canonica, Ius Ecclesiae 26 (2014) 511-534; J. A. NIEVA, El bautizado que contrae matrimonio sin fe no necesariamente excluye el consentimiento matrimonial, Ius Canonicum 54 (2014) 521-565; M. A. ORTIZ, Fe y matrimonio, en J. BosCH (ed.), Cuestiones actuales de Derecho Canónico y Derecho Eclesiástico del Estado: Actas de las XXXIV Fornadas de Actualidad Canónica, organizadas por la Asociación Española de Canonistas en Madrid, 23-25 de abril de 2014, Dykinson, Madrid 2015, 266-292: especialmente 289-291. 
fiesta la nulidad, sin necesidad de una investigación o una instrucción más precisa (cfr. 1683, 2; SA 3, 1, a), como indica expresamente SA.

\subsection{La brevedad de la convivencia conyugal}

Las cuatro líneas que dedica el SA a esta circunstancia son especialmente claras, porque subrayan una vez más que el mismo hecho -la brevedad de la convivencia conyugal- puede ser muestra o manifestación de una nulidad matrimonial que provenga de capítulos diversos. El texto subraya primero la relevancia jurídica del supuesto señalando que «puede ser indicador particularmente evidente»: así pues, debe entenderse como «un indicador», es decir, como un indicio, como una señal de advertencia, etc. porque la particular evidencia no se refiere a la prueba del capítulo de nulidad con el que esté eventualmente vinculado, sino a su valor como indicador o indicio. Respecto a las posibles conexiones con diversos capítulos de nulidad, el texto señala la simulación, o una «forma de reacción en el caso de la condición, error o dolo, intolerabilidad de la convivencia por anomalías psíquicas» (SA 3, 1, c).

El texto en castellano puede presentar cierto inconveniente al no quedar muy claro si los términos «forma de reacción» se refieren solamente a la condición, o también al «error, dolo o intolerabilidad de la convivencia». Sin embargo, el texto italiano nos resuelve la duda, puesto que habla expresamente de «forma di reazione nelle fattispecie di condizione, errore o dolo, intollerabilità della convivenza per anomalie psichiche» ${ }^{14}$, es decir, utiliza el plural y por tanto deja claro que la circunstancia de la que se habla -la brevedad de la convivencia conyugal- puede constituir una forma de reacción ante casos de condición, o de error, o de dolo, o de intolerabilidad de la vida conyugal.

En sustancia, estas breves líneas del SA están muy bien pensadas y expuestas, ya que el supuesto de base -la brevedad de la convivencia- en cuanto manifestación posible de una nulidad matrimonial, podría ser expresión de una determinación previa a propósito del objeto de la propia voluntad matrimonial (que ocurriría exclusivamente en el in fieri), como es el caso de la voluntad simulatoria. Sobre todo se referirá, si acaso, a supuestos de simulación total (p. e. matrimonios de complacencia o de conveniencia, etc. $)^{15}$. También podría refe-

\footnotetext{
${ }^{14}$ La cursiva es mía.

15 Cfr. J. Ferrer Ortiz, Valoración de las circunstancias que pueden dar lugar al proceso abreviado, Ius Canonicum 56 (2016) 176.
} 
rirse a una simulación parcial (p. e. por exclusión de la indisolubilidad o de la fidelidad), pero parece menos compatible con el perfil psicológico de quien realmente ha querido contraer un vínculo (aunque fuera sin alguno de los fines o de sus elementos esenciales). En uno u otro caso, «no basta con la confesión de uno o los dos esposos. Por esta razón se distingue entre Prueba Directa, cuando se cuenta con la confesión judicial y extrajudicial del simulante, unida a declaraciones de testigos o incluso documentos; y Prueba Indirecta, cuando se carece de ella y se acude a presunciones junto con un análisis de las circunstancias antecedentes, concomitantes y subsiguientes. Para la prueba es, asimismo, constante [en la doctrina y en la jurisprudencia] la mención de la causa contrabendi y la grave o gravísima causa simulandi -próxima y remota- unida a las circunstancias antecedentes, concomitantes y subsiguientes» ${ }^{16}$.

Pero la brevedad de la convivencia conyugal también podría mostrar una reacción a un suceso desconocido o inesperado del in facto esse. Este supuesto, a su vez, podría darse de dos formas: en la primera de ellas estaría conectado con un hecho en parte ajeno -en cuanto desconocido- y en parte vinculado a la propia voluntad antecedente: como la incertidumbre ante un hecho que se ignora y al que se vincula positivamente la voluntad de contraer -condición-, o el desconocimiento en caso del error en una cualidad directa y principalmente pretendida. En la segunda forma de este supuesto, la brevedad de la convivencia conyugal estaría manifestando la reacción ante la intervención de otro: sería el caso del dolo o el caso de la existencia previa de una anomalía psíquica que hace imposible la vida conyugal. En todos estos casos, el contrayente, de algún modo, se ve como sujeto pasivo, en el sentido de que la nulidad no sería causada exclusivamente por un acto de su libertad -como en la voluntad simulatoria- sino que dependería también de factores o conductas externas ${ }^{17}$.

No se ha definido lo que debe entenderse por «brevedad» en tiempos de plazos temporales. Es claro que sería breve un plazo menor de un año. Otros

${ }^{16}$ C. GUZMÁn PÉREZ, La exclusión del bonum prolis en la reciente jurisprudencia de la Rota Romana, en J. Bosch (ed.), Cuestiones actuales de Derecho Canónico y Derecho Eclesiástico del Estado: Actas de las XXXIV Fornadas de Actualidad Canónica, organizadas por la Asociación Española de Canonistas en Madrid, 23-25 de abril de 2014, Dykinson, Madrid 2015, 141.

17 Cfr. Sententia c. Staffa, 29-XI-1975, Periodica 66 (1977) 323, en la que señala que «brevitas durationis vitae coniugalis semper habita est uti indicium nullitatis vinculi» $\mathrm{y}$ a continuación hace referencia a diversos capítulos de nulidad de los que puede ser manifestación. Interesa recalcar la calificación de «indicium», lo que muestra la necesidad de que concurran otros hechos y/o testimonios para alcanzar una prueba suficiente (sobre el particular, cfr. H. FRANCESCHI, La riforma e il regime delle nullità matrimoniali, p. 7, en prensa). 
han apuntado a cinco, e incluso a diez años. En realidad no resulta necesario tratar de fijar un plazo, puesto que no se trata de la determinación de una norma jurídica, sino que simplemente se está citando como ejemplo una circunstancia que puede contribuir a mostrar que cabe una prueba manifiesta de una nulidad matrimonial causada por algunos capítulos referidos al consentimiento. Además, en el caso de la condición o del error en cualidad directa y principalmente pretendida, o el dolo, el tiempo relevante es sobre todo el que transcurre entre el descubrimiento del hecho y la reacción del esposo. «En estos casos, una prueba importante, aunque no única, puede ser la inmediata interrupción de la vida en común (...) cómo actuó el sujeto en el momento en que verifica que no se cumplió el objeto de la condición o descubre el error en una cualidad directa y principalmente pretendida del otro contrayente o el error dolosamente causado» ${ }^{18}$.

En cuanto al bien jurídico que se está protegiendo, en algunos de estos casos es la libertad de la voluntad real de las partes cuando de algún modo se opone al verdadero objeto del pacto conyugal (simulación) o cuando se vincula subjetivamente de un modo u otro a la existencia de un hecho o cualidad determinados (condición, o error en cualidad directa y principalmente pretendida). El bien jurídico que se está protegiendo en el caso del dolo es la libertad de la voluntad matrimonial que ha sido seriamente lesionada a través de una manipulación en el proceso de formación, por parte del otro contrayente o de un tercero. En el caso de la incapacidad el bien jurídico que se está protegiendo es el dominio de sí necesario para poner en ejercicio el ius connubii; en este caso se está defendiendo a los dos contrayentes (la parte incapaz y la otra) y también la verdad del matrimonio mismo: no se trata por tanto de que la «intolerabilidad de la convivencia» pueda producir la nulidad del pacto conyugal, sino de que pueda ser muestra de una incapacidad psíquica de las que habla el canon 1095.

Por lo demás, hay que considerar también que la brevedad de la convivencia matrimonial -en cuanto tal- puede responder a factores imponderables o a conductas libremente escogidas -aunque irresponsables o inmorales- que no manifiestan ni expresan la existencia de nulidad alguna ${ }^{19}$. Más bien podría

18 J. FerRer Ortiz, Valoración de las circunstancias que pueden dar lugar al proceso abreviado, Ius Canonicum 56 (2016) 176.

19 Sententia c. Stankiewicz, 26 ianuarii 2001, RR.Dec., vol. XCIII, n. 24, 103: «Nihilominus tamen agendi modus Conventi post nuptias ac brevitas convictus coniugalis ab eodem viro interrupti, iure requisitum positivum voluntatis actum contra bonum sacramenti, nostro in casu omnino deficientem, supplere non valent». 
decirse que cuando parece clara una simulación -u otro de los supuestos de los señalados en el SA-, si se añade la realidad de una vida conyugal breve, puede contribuir a consolidarse una prueba ${ }^{20}$. En todo caso, a efectos de la prueba se deben tener en cuenta los elementos esenciales de cada uno de los capítulos de nulidad. Por ejemplo, en la simulación, en la condición, o en el error en cualidad directa y principalmente pretendida, habrá que probar de modo manifiesto el contenido completo de la voluntad previa al matrimonio; en el dolo, habrá que mostrar no sólo un engaño destinado a obtener el consentimiento, sino también la existencia de una verdadera manipulación que llegó a conformar la voluntad matrimonial del contrayente y la seriedad de la lesión producida en la vida conyugal in casu. Es esta prueba la que no parece sencillo que exista de modo manifiesto y pueda facilitar plena evidencia sin necesidad de ulteriores investigaciones ${ }^{21}$.

Por último, habría que añadir que también un caso de miedo o de violencia podría dar lugar a una convivencia conyugal breve y quizá la prueba del miedo o de la violencia podría ajustarse más fácilmente a las exigencias de evidencia que piden las normas. Se puede recordar finalmente que el nexo causal debe medirse según la verdad objetiva de los hechos y el bien jurídico que se lesiona en cada caso, no según el impacto subjetivo producido por el relato de unos hechos dramáticos o aun injustos.

\subsection{El aborto procurado para impedir la procreación}

El SA lo califica como «indicio vehemente de voluntad simulatoria». Aquí estamos tratando de un supuesto delictivo que con palabras del mismo SA «demuestra un enorme distanciamiento de la moral de la Iglesia por parte del sujeto, que a su vez puede ser indicador de una carencia esencial de fe».

${ }^{20}$ Sententia c. Monier, 18 februarii 2000, R.R.Dec., vol. XCII, n. 16, 193: «Circumstantiae quae in actis exstant ample confirmant mulieris actum voluntatis et proportionatam causam simulandi. Praesertim brevitas convictus, constans usus et abusus medii anticonceptionalis; et ultimo inmediata reassumptio relationis cum Petro, statim ac convictus instauratus fuit». Parece que en este caso -como quizá ocurra en la mayoría de los supuestos- la brevedad de la convivencia adquiere su mayor fuerza precisamente en el conjunto de los demás indicios y pruebas.

${ }^{21}$ M. AlENDA SALINAS señala la necesidad de distinguir «si esa breve convivencia de los cónyuges es mera consecuencia de la irreversibilidad del relatado fracaso, sin voluntariedad de los mismos al respecto; o, por el contrario, la brevedad de las nupcias se debe a la voluntad de las partes, en virtud de una causa impuesta a tal fin por una de ellas, al menos» (iNuevas causas..., cit., 17-18). 
De la carencia de fe hemos hablado en su momento. Ahora interesa recalcar la gravedad del delito de aborto, no ya porque vaya contra la moral católica, sino porque su propia índole consiste en dar muerte a un inocente. Esto viene remarcado por la presentación misma de la circunstancia de que tratamos, en el artículo 14: «el aborto procurado para impedir la procreación ${ }^{22} »$.

Es claro que todo aborto provocado pretende «impedir la procreación» o -más exactamente-, en sí mismo pretende acabar con el desarrollo de una vida ya presente en el seno materno. Sin embargo, se entiende que el añadido «para impedir la procreación» puede servir para matizar dos cuestiones, acerca de la intencionalidad del sujeto, que es lo que primordialmente interesa desde el punto de vista del consentimiento matrimonial: la primera es que, aunque todo aborto constituye un atentado contra la vida humana, cabría pensar en casos en que esa intención no fuera la principal -o incluso no fuera deseada por sí misma-: por ejemplo, en el caso de un aborto procurado principalmente para salvaguardar la salud de la madre, o por presiones exteriores; en ese caso, ciertamente existiría el mal moral, pero no significaría una manifestación de una voluntad previa de exclusión de la prole (no estaría presente esa dimensión jurídica respecto al acto de voluntad del consentimiento). O podría ser que el aborto fuera provocado después de años de vida conyugal normal y habiendo tenido descendencia más o menos numerosa: en ese caso estaríamos ante una intención «sobrevenida» tiempo después del pacto conyugal y por tanto irrelevante como evidencia de una exclusión de la prole. La segunda cuestión es que el añadido «para impedir la procreación» viene a subrayar que no es tanto el aborto en sí -por grave que sea- lo que puede apuntar a una posible nulidad matrimonial, sino la relación que pueda existir entre la intencionalidad del delito y la intencionalidad del consentimiento: «Se deberá verificar, a partir de las declaraciones de las partes, que el aborto procurado haya sido movido por la firme voluntad de excluir la prole» ${ }^{23}$.

En este sentido, «el distanciamiento de la moral de la Iglesia» o la posible «carencia de fe» citados en el SA deben considerarse como posible caldo de cultivo de una causa simulandi remota, porque se trata de circunstancias morales de la persona en general, en cuanto tal persona, y no específicamente re-

22 La cursiva es mía. Vid. A. M. VEGA GutiÉRREZ, La exclusión de elementos esenciales y propiedades del matrimonio, en P.-J. VILADRICH - J. Escrivá - J. I. BAÑARES - J. Miras (dirs.), Matrimonio. El Matrimonio y su expresión canónica ante el III Milenio, Instituto de Ciencias para la Familia, Eunsa, Pamplona 2000, 1219-1265.

23 A. Bunge, Presentación del nuevo proceso matrimonial, cit., 18. 
feridas al matrimonio. Pero lo que debe ser probado es el acto excluyente propio de la voluntad simulatoria, es decir, la intención clara y antecedente de no donarse a sí mismo como potencial progenitor y en consecuencia de no aceptar la mutua copertenencia y el derecho de la otra parte a una intimidad conyugal abierta a la vida. El aborto llevado a cabo podrá -en su caso- completar una prueba de la simulación, pero no tiene contenido ni fuerza para demostrarla por sí mismo. La negación del bien de una vida concebida es gravemente inmoral -y en sí misma criminal-, pero -también en sí misma- es distinta de la negación del bonum prolis ${ }^{24}$. El aborto es posterior a las nupcias y las intenciones anteriores al pacto conyugal deben probarse con todo el conjunto de hechos (y en su caso, testimonios fiables) ocurridos en el transcurso íntegro de la vida conyugal.

\subsection{La obstinada permanencia en una relación extraconyugal al momento de las nupcias o en un tiempo inmediatamente sucesivo}

En el SA se observa que este hecho «puede considerarse un indicio evidente de la negación de la obligación de la fidelidad; puede combinarse con el rechazo a tener relaciones íntimas con el legítimo cónyuge. En este caso, también puede haber pruebas documentales (relaciones de investigación privadas, cartas, tabularios de comunicaciones telefónicas o electrónicas)» (SA 3, 1, c).

Evidentemente al referirse a la «negación de la obligación de la fidelidad» no se está haciendo una referencia al hecho en sí de la relación ilegítima, al incumplimiento de una voluntad de fidelidad asumida, sino a la exclusión de la fidelidad en el momento del consentimiento, ya que la voluntad simulatoria -que sería la causa de nulidad aducible en este caso- consiste precisamente en una intención actualmente presente en el in fieri.

Por su parte, la expresión «puede considerarse un indicio evidente de la negación de la fidelidad», hay que entenderla adecuadamente. En primer lugar «puede considerarse» no es equivalente a «debe»: justamente marca la posibilidad, frente a la necesidad; en segundo lugar, conviene tener en cuenta que lo evidente no es la negación de la fidelidad, sino el indicio como tal indicio. El

${ }^{24}$ Vid. C. GUZMÁn PÉREZ, La exclusión del bonum prolis en la reciente jurisprudencia de la Rota Romana, en J. Bosch (ed.), Cuestiones actuales de Derecho Canónico y Derecho Eclesiástico del Estado: Actas de las XXXIV Fornadas de Actualidad Canónica, organizadas por la Asociación Española de Canonistas en Madrid, 23-25 de abril de 2014, Dykinson, Madrid 2015, 127-179. 
valor del indicio surgirá en primer lugar de la prueba de los hechos-que debe ser terminante- acerca de la exclusión misma, no del hecho en sí $^{25}$. Con todo, por la más estrecha relación que puede existir en este supuesto entre los hechos y la exclusión previa, habrá que atender al conjunto de indicios y pruebas que hagan concluyente la voluntad de excluir la fidelidad y atender especialmente a su fiabilidad ${ }^{26}$. Particularmente relevante será la prueba de la publicidad y continuidad de los hechos y la identidad del amante, pues la infidelidad con varias personas, aunque sea repetida, difícilmente podrá probar la exclusión previa sin ulteriores investigaciones, propias del proceso ordinario. Por el contrario, en este supuesto, si se prueban de modo claro la continuidad -e incluso la publicidad- de los hechos anteriores y posteriores con idéntica persona, y existe una confesión fiable por parte del simulante, es más fácil aceptar la admisión de la causa por el proceso brevior.

Por lo demás, como se ha señalado, la referencia a una relación «al momento de las nupcias o en un tiempo inmediatamente sucesivo», oscurece la claridad del supuesto, que ciertamente se entendería mejor si dijese «al momento de las nupcias y en un tiempo inmediatamente sucesivo ${ }^{27}$. La razón estriba en que es más difícil una prueba terminante cuando la conducta infiel ha comenzado después de contraído el matrimonio. Como es obvio, en estos supuestos se protege a la vez el bien de la auténtica voluntad de las partes y el bien del matrimonio verdadero.

\subsection{El ocultamiento doloso de la esterilidad o de una grave enfermedad contagiosa o de hijos nacidos en una relación precedente o de un encarcelamiento}

El ejemplo del dolo acerca de la esterilidad previamente conocida está incluido en el propio Código. Los otros supuestos constituyen ejemplos de cualidades cuya existencia - por su propia naturaleza- podría afectar gravemente al consorcio conyugal. Pero son de naturaleza diversa.

${ }^{25}$ P. BIANCHI señala un caso en que parecían darse las condiciones adecuadas, pero en el que la declaración de una de las partes no logró aportar ninguna prueba que diera constancia de sus palabras, y la del amante estuvo llena de contradicciones (cfr. ¿̨Cuándo es nulo el matrimonio?, Pamplona $22007,115-117)$.

26 Vid. M. GAS AIXENDRI, La exclusión del bonum fidei y su prueba. Doctrina y jurisprudencia, Ius Canonicum 51 (2011) 207-234.

27 Cfr. H. FRANCESCHI, La riforma e il regime delle nullità matrimoniali, cit., 8. 
Como es sabido, el capítulo de nulidad por dolo protege el bien jurídico de la libertad de la parte en la elección del cónyuge. En esos supuestos, debe probarse una cadena de hechos conectados en su causalidad y en su incidencia en el proceso de formación de la voluntad de contraer matrimonio ${ }^{28}$. En primer lugar, en cuanto a la parte activa, se debe probar que existió un engaño o manipulación consciente de la verdad. En segundo lugar, es necesario probar que el agente provocó el engaño y que lo hizo específicamente para obtener el consentimiento en el pacto conyugal. En tercer lugar, en la parte paciente hay que probar que la acción dolosa -que lógicamente puede ser por omisiónprovocó el error en la cualidad de que se trata. En cuarto lugar se requiere probar que tal error intervino en la decisión de contraer del paciente, al menos como error causam dans $^{29}$. En quinto lugar, hay que comprobar que la cualidad acerca de la cual se indujo el error por su propia naturaleza puede provocar graves perturbaciones en el consorcio conyugal. Y en sexto lugar, hay que comprobar que efectivamente tales perturbaciones existieron y fueron causadas por la presencia -o la ausencia- de la cualidad sobre la que se erró.

Cabalmente puede decirse, a la luz de esta cadena de conexiones causativas, que los supuestos incluidos en el artículo 14 son de naturaleza diferente. Veámoslo en cada caso. Una enfermedad contagiosa afecta de modo actual y grave a la persona y además, por su propia índole, afectaría del mismo modo al consorte. Subrayaría que el supuesto parece referirse a una enfermedad duradera e incurable (al menos en su capacidad de contagio). Tal supuesto no sólo afecta a la vida en común en general, sino a la intimidad de la vida conyugal. Precisamente por eso la obligación de exponerla es grave y su omisión no puede dejar de ser intencional. Por eso en este supuesto se encuentran como en núcleo casi todas las características del dolo. Digo casi todas las circunstancias porque se podría dudar en el caso de que el hecho del descubrimiento del dolo no hubiera dado ocasión a alteración alguna de la relación y con el perdón de la parte engañada la vida conyugal hubiera proseguido pacíficamente (pensemos, por ejemplo, en que -por cualquier razón- en un momento determinado la enfermedad se hubiese curado o hubiese dejado de ser contagiosa, etc.). Con

${ }^{28}$ Cfr. M. Alenda Salinas, ¿¿Nuevas causas..., cit., 37-39.

${ }^{29}$ Es necesario «que esta ocultación se haya hecho con la finalidad de obtener de la comparte el consentimiento matrimonial. Debe poder deducirse el nexo de causalidad entre el dolo y el consentimiento matrimonial, de modo tal que pueda atribuirse la celebración del matrimonio a un dolo directo» (A. Bunge, Presentación del nuevo proceso matrimonial, cit., 18). 
todo, el requisito de que las partes estén previamente de acuerdo para pedir o aceptar el proceso brevior hace difícil que se dé un supuesto de este tipo.

Por ello, una prueba manifiesta y rotunda de tal enfermedad, de su conocimiento y de su ocultación tendría un valor muy significativo para probar el propio capítulo de nulidad por dolo.

El supuesto de la ocultación de hijos nacidos en una relación precedente, sin embargo, es diferente. El hecho concreto manifiesta que hubo una ocultación dolosa de una cualidad. Y puede resultar fácil la prueba de la existencia de hijos anteriores procedentes de otra unión. Pero la prueba de la intención dolosa expresamente para obtener el consentimiento, el efecto real que pudo tener el error en la voluntad de contraer del otro cónyuge y la capacidad para provocar perturbaciones graves en el consorcio no están incluidos en el hecho mismo. Y esta falta de evidencia de las conexiones causales haría necesario recurrir al proceso ordinario. Pensemos en la variedad de situaciones que podrían darse: por ejemplo, si los hijos habidos en la relación anterior ya murieron; o si son mayores e independientes; si la otra parte también los hubiera tenido; si por el carácter y situación de la parte engañada no le importara ni afectase el hecho de que se trata, etc.

Obviamente también puede ocurrir que en este supuesto -la ocultación de hijos de una unión precedente- se den todas las condiciones que requiere la prueba del dolo. Lo que parece difícil es que pudieran probarse de modo manifiesto todos los nexos causales requeridos sin necesidad de investigación alguna.

En el último supuesto que se apunta, el de la ocultación del encarcelamiento, probablemente es más difícil todavía que se pueda llegar «de manera inequívoca» a toda la cadena de requisitos desde el momento de la demanda y con sólo los documentos. Se puede probar con cierta facilidad la existencia del error en la parte engañada y la intención dolosa de la comparte, pero la prueba de su conexión con la intención matrimonial, el modo en que afectó a la voluntad matrimonial y la conexión con las graves perturbaciones del consorcio tal vez no resultan compatibles con el carácter inmediato y expeditivo del proceso brevior. También aquí debemos pensar que caben muchas circunstancias y muchas hipótesis distintas: no es lo mismo un delito que otro; no es lo mismo haber estado encarcelado pocas semanas o muchos años; que hubiese ocurrido recientemente o hace mucho tiempo; no es lo mismo que de ese hecho se siguieran unas consecuencias u otras; no es lo mismo quién sea el otro cónyuge, qué ideas y convicciones tenga, qué tipo de vida haya llevado, cuánto le haya afectado la información de ese dato del pasado y cómo haya influido en la vida conyugal, etc. 


\subsection{La causa del matrimonio extraña a la vida conyugal o consistente en el embarazo imprevisto de la mujer}

La cuestión de por qué una mujer y un varón deciden contraer matrimonio no tiene una respuesta: lo que se ha llamado el finis operantis, es decir, lo que actúa en el terreno de las causas subjetivas que impelen a la decisión del matrimonio con alguien concreto, permanece necesariamente abierto, porque el ámbito resulta tan amplio como la misma libertad humana. La conexión entre mil factores posibles y la génesis del acto de voluntad matrimonial no responde a reglas ni puede encuadrarse en esquemas prefijados. No cabe tampoco regular o prohibir en ese terreno; nadie puede regular por norma si es mejor decidir el matrimonio por la belleza del otro contrayente, por su afectividad, por sus capacidades personales y profesionales, por su comprensión o por su serenidad y equilibrio. Los límites, por tanto, serán los bienes jurídicos que protege el capítulo de nulidad por simulación total o exclusión del matrimonio mismo, al que ya nos hemos referido anteriormente: la verdad del matrimonio y la libertad de los contrayentes.

En efecto, sabemos que el derecho canónico respeta absolutamente la voluntad auténtica -real- de los contrayentes, aunque quieran algo inconveniente o contradictorio con la misma naturaleza del matrimonio: precisamente esa contradicción no podrá dejar de tener consecuencias jurídicas en lo que respecta al pacto conyugal. Una cosa es por qué quiero casarme con esta persona, y otra es si lo que quiero con esta persona es de verdad el matrimonio, es decir, la entrega y aceptación como esposos en orden a los fines propios del consorcio conyugal. La primera cuestión «por qué quiero casarme con esa persona», de por sí no es relevante. Lo que sí es importante es si el acto de voluntad del contrayente contenía enteramente la verdad objetiva de la conyugalidad.

¿En qué sentido, entonces, cabe hablar de un indicio manifiesto cuando «la causa del matrimonio [es] extraña a la vida conyugal»? ¿Hasta qué punto pueden individuarse y contabilizarse cada una de las causas subjetivas concurrentes y su respectivo peso en la decisión final de contraer matrimonio con alguien? ¿Puede una persona casarse primariamente por compasión? ¿Debería uno no casarse si en la decisión pesa la consideración de los medios materiales de que dispone la otra parte? ¿A partir de un conocimiento básico, bastaría un gran apasionamiento para decidirse a contraer?

Lo que aquí pretendemos hacer ver es que, tratándose de un fin totalmente subjetivo, no es fácil predeterminar cuándo es «totalmente ajeno a la 
comunión de vida conyugal», como dice el SA $(3,1, \mathrm{c})$. Este texto recoge concretamente tres ejemplos del supuesto: la adquisición de ciudadanía, la legitimación de la prole y la adquisición de beneficios económicos. La adquisición de la ciudadanía puede incluirse entre los ya referidos matrimonios de complacencia. La legitimación de la prole puede ser una causa subjetiva que lleve a excluir el matrimonio mismo aceptando simplemente la apariencia externa; pero ciertamente lo uno no lleva a lo otro de modo necesario, aunque implica una posibilidad teórica. Es decir, querer la legitimación de la prole no incluye de por sí el no querer el vínculo matrimonial, y querer el vínculo conyugal no exige ni excluye de por sí -en su caso- querer legitimar la prole. Por eso lo que hay que demostrar no es tanto la existencia de una causa determinada en su motivación subjetiva, sino la vaciedad o negación de su voluntad matrimonial. Para ello habría que considerar también lo ocurrido en el in facto esse: la duración de la unión conyugal, su desarrollo, las causas de la crisis de convivencia, etc., pues es difícil que una simulación total de este tipo no haya tenido repercusiones serias y próximas al inicio mismo de la vida conyugal; en este sentido, cuanto más normal y prolongada hubiera sido la convivencia marital, menos posibilidad existiría de justificar la nulidad fundada en este capítulo, al menos por el proceso brevior.

Por tanto, no parece que la cuestión más relevante sea la «extrañeza» (de la causa subjetiva que impele a la decisión de contraer) respecto a la vida conyugal. El concepto de «totalmente ajeno a la comunión conyugal» no sólo no es objetivo ni puede serlo, sino que legítimamente puede variar mucho en función de las personas: de sus usos y costumbres, carácter, preferencias y prioridades, valores, coherencia, y un amplio etcétera. Se trata de que la propia conexión de cualquiera de los fines operantis con la decisión de contraer depende totalmente del sujeto y la forma en que se oponga internamente a la voluntad de conyugarse depende también del sujeto de forma exclusiva. Por eso la claridad o evidencia manifiesta que necesita un supuesto de este tipo para iniciar la causa de nulidad por el proceso brevior normalmente exigirá una tarea más compleja y más investigaciones de las que pueden tener lugar en el momento prejudicial.

Tal vez por eso el SA dice que estos supuestos pueden «manifestar la posibilidad de que uno o ambos cónyuges no hayan querido realmente contraer matrimonio, entendido como donación interpersonal de los contrayentes» ${ }^{30}$.

\footnotetext{
${ }^{30}$ La cursiva es mía.
} 
Se subraya el carácter de «posibilidad»y, no sin apoyarse en la praxis jurisprudencial, se añade que «esta circunstancia frecuentemente concurre con otras, como la brevedad de la vida conyugal y la iniciativa de la separación y del divorcio». En efecto, la multiplicación de los indicios puede manifestar una mayor evidencia: permanece, en todo caso, la dificultad de que su prueba sea taxativa, terminante e inmediata.

El caso del embarazo inesperado. Aquí estamos en una situación diversa. No se trata de la posible interferencia entre uno de los fines operantis y la verdad del matrimonio, sino de una circunstancia a la vez externa y objetiva -el embarazo de la mujer- y subjetiva e interna: la atribución de la maternidad y paternidad a la pareja de progenitores. Que una mujer y un varón que van a ser padres -o lo han sido- se casen, evidentemente no muestra la nulidad del matrimonio: ahí no sólo estamos en el ámbito de las causas subjetivas que legítimamente pueden llevar o inducir a un contrayente a tomar la decisión de casarse, sino incluso en una conducta objetiva que en principio podría ser deseable y/o aconsejable en no pocos casos. Es verdad que lo ideal es que la conyugalidad se instaure en primer lugar y después se derive de ella la maternidad y paternidad; pero también es verdad que el hecho de haber engendrado un hijo en común, nada obsta para que los progenitores se unan en el consorcio conyugal.

La cuestión puede venir por otras circunstancias complementarias: el tiempo que duró la relación previa al matrimonio; el proyecto de vida en común que tenían; la actitud ante la posibilidad de la concepción, y luego ante la vida ya concebida; la reacción suya y del entorno familiar y social ante el embarazo inesperado. Parece que evoca el tema del miedo -quizá sobre todo el temor reverencial- o de la «falta de libertad interna», que suele incluirse en el concepto de grave defecto de discreción de juicio. Si bien es cierto que el supuesto de contraer ante la Iglesia por el embarazo previo y el miedo a la familia es cada vez menos plausible en la civilización occidental de hoy. En cualquier caso, el problema puede ser encontrar, antes del proceso mismo, unas pruebas que manifiesten de modo patente la conexión causal y cerrada entre el embarazo no deseado, la exclusión de la voluntad matrimonial de modo positivo y la causa simulandi que pudo existir, en el caso de que se propusiera la demanda por simulación total. Ahí es donde habrá que ver si se dispone de una documentación suficientemente completa y fiable acerca de la relación de noviazgo y de los hechos acontecidos después del pacto matrimonial: especialmente convendrá tener evidencia de que uno o los dos contrayentes no se han 
considerado cónyuges después de la boda ni han sido conscientes de haber asumido una nueva situación en su relación intersubjetiva. Sería más difícil todavía llegar a una prueba manifiesta del miedo y, sobre todo, la falta de libertad interna, con todos los matices y la complejidad que estos casos plantean.

En cualquiera de los casos, «debe ser claro que el contrayente excluye a la otra parte como cónyuge y pretende con su consentimiento algo bien distinto del matrimonio, que incluye el elemento de la comunidad de vida y amor entre las partes. Debe ser evidente que la voluntad del contrayente no pretende en absoluto el fin del matrimonio, sino sólo una simulación del matrimonio, sin intención de obligarse de ningún modo» ${ }^{31}$.

\subsection{La violencia física ejercida para arrancar el consentimiento}

El SA introduce el tema recordando que «el temor inducido externamente es uno de los motivos clásicos del matrimonio» ${ }^{32}$. Y añade: «en el caso de producirse verdaderos y propios actos de violencia o daño por la parte contumaz, constituye un gravísimo indicio de invalidez del consentimiento emitido $(3,1, \mathrm{c}) \gg$.

Aquí resulta curiosa y a la vez clarificadora, la mezcla del temor y la violencia, que aparecen tratados también conjuntamente en el canon 1103. Tradicionalmente se ha entendido que la violencia se refería directamente a la manifestación física del consentimiento y por tanto se trataba de hecho de un capítulo de nulidad residual, muy difícilmente existente en la práctica. Sin embargo, también ha habido autores que han señalado que una violencia infligida de continuo puede afectar al consentimiento aunque no se manifieste literalmente en el momento exacto de emitirlo ${ }^{33}$.

Por eso resulta clarificadora la mezcla de la violencia y el miedo en la explicación de este supuesto, porque indica que no es necesaria una violencia fí-

31 A. Bunge, Presentación del nuevo proceso matrimonial..., cit., 19.

32 Obviamente se está hablando en el contexto de las posibles causas de nulidad.

33 Cfr. P.-J. Viladrich, El consentimiento matrimonial, Eunsa, Pamplona 1998, 318. El autor señala que lo definitivo -y a la vez, lo diferencial- de la violencia como caput nullitatis consiste en «la vis compulsiva, absoluta, corpori illata», que muestra su carácter irresistible en «la fuerza que consigue la rendición y sometimiento somático del sujeto paciente, el cual ni siquiera elige el matrimonio en vez de los daños, aunque lo haga por coacción, sino que se limita a expresar con su cuerpo la voluntad del incutiens sin posibilidad de resistirse». Cfr. J. FERRER OrTIZ, Valoración de las circunstancias que pueden dar lugar al proceso abreviado, Ius Canonicum 56 (2016) 184. Los casos que ofrece la Rota Romana de la violencia física directa son escasísimos. 
sica en el momento del pacto conyugal, sino que la violencia previa puede producir un estado de miedo que lleve a aceptar un matrimonio con el único objeto de evitar un mal mayor: habría entonces una derivación de un capítulo al otro. Pero el texto del SA también se puede referir, p. e., a unos malos tratos continuados que llevaran a simular un consentimiento que de ninguna manera se desea: en ese caso el miedo actuaría como causa simulandi. De hecho, parece que podría solicitarse la demanda por cualquiera de los tres capítulos de nulidad. El bien jurídico protegido sin duda se trata de la libertad de los contrayentes en el proceso de formación del acto de voluntad matrimonial: pero el modo de lesionarse, sus efectos y el modo de defenderse ante esa agresión pueden ser diversos y a ello responden los diferentes capítulos de violencia, miedo y simulación.

En el capítulo de violencia, en definitiva se trata de que externamente le hagan manifestar a un contrayente un consentimiento matrimonial que no es suyo. En el caso del miedo, la amenaza de un mal producido por causa humana y libre que plantea el matrimonio como única solución factible, conduce al contrayente a aceptar contraer y a poner él mismo el consentimiento matrimonial. Por tanto no se trata de una ausencia de consentimiento, sino de un consentimiento existente pero que el legislador -concretando el mismo derecho natural- entiende insuficiente por la manipulación provocada: de ahí que, en este caso peculiar, existe un consentimiento real, pero ineficaz por la falta de arraigo en el sujeto que lo emite. En el caso de la simulación, la violencia actúa también creando una situación de miedo, pero este miedo no enajena el consentimiento sino que lleva al contrayente a emitir su signo externo rechazándolo en su interior. De ahí que, paradójicamente, siendo el supuesto el mismo, el capítulo de miedo es incompatible con el capítulo de violencia y con el de exclusión del matrimonio mismo.

En la práctica, en estos supuestos todo dependerá de las pruebas y los testimonios acerca de la violencia (gravedad, duración, permanencia: el SA incluye expresamente como ejemplos los certificados médicos y las «verbales» ${ }^{34}$ de las autoridades policiales) y su vinculación con el consentimiento matrimonial. Quizá este punto sea también una crux iudicum en su aplicación, pues cuesta imaginar cómo comprobar esa vinculación directa entre la violencia de

34 En italiano el término «verbale» significa, por ejemplo relaciones, declaraciones o documentos. En castellano no existe como sustantivo. En cualquier caso, se entiende bien por el contexto. 
uno sobre el otro y su simultánea intención «de arrancarle» el consentimiento para convertirlo en cónyuge ${ }^{35}$.

Cabe plantearse por qué se incluyó este ejemplo, que podría encuadrarse directamente -si no identificarse- con el capítulo de nulidad del canon 1103. Por lo que se puede deducir del texto del SA, probablemente se está pensando en concreto en la llamada violencia de género, entendida estrictamente como malos tratos físicos continuados. En este sentido estaría aludiendo a una forma de ejercicio de la violencia física quizá más peculiar -o más extendida- en la actualidad en no pocas partes del mundo, independientemente de su nivel de desarrollo económico o cultural. Por lo demás, el supuesto incluye adecuadamente el término «violencia física», pues si bien cabe otra especie de violencia, probablemente no sería igualmente susceptible de prueba manifiesta y directa.

\subsection{La falta de uso de razón comprobada por documentos médicos}

Por un lado la falta de suficiente uso de razón no es un supuesto de hecho, como vimos al inicio, sino un capítulo de nulidad. Puede sorprender, por eso, encontrarlo dentro de la enumeración del artículo 14 de las RP. Sin embargo, el SA viene a aclarar lo que posiblemente fue la razón de su inclusión y también el objetivo que persigue y las condiciones que exige.

El texto del SA no tiene reparo en afirmar que «la incapacidad consensual por causas psíquicas requiere generalmente una profunda investigación científica pericial que únicamente puede realizarse adecuadamente en el proceso ordinario». Parece que el principio general es claro: las causas de nulidad por incapacidad habitualmente se tramitarán por el proceso ordinario, porque son complejas y exigen averiguaciones ulteriores.

Por tanto, se trata aquí de una situación muy particular, cuyos requisitos señala el mismo SA de la siguiente manera: a) gravísimas patologías; b) debidamente documentadas (historiales clínicos, pericias psiquiátricas en sede civil); c) que respondan a una jurisprudencia consolidada; d) que permitan (según tal jurisprudencia) alcanzar un juicio positivo sin ninguna clase de duda

${ }^{35}$ El término utilizado en el original italiano «estorcere» indica también una acción agresiva. Se puede considerar sinónimo de «togliere con forza, togliere con inganno, portar via, sottrarre, strappare, rubare, rapinare, derubare, carpire» (Dizionario dei Sinonimi e dei Contrari, http://dizionari.corriere.it/dizionario_sinonimi_contrari/E/estorcere.shtml, consulta: 3-XI-2016). A. BUNGE, Presentación del nuevo proceso matrimonial, cit., 19, aclara: «deberá tratarse de demostrar con pruebas inexpugnables y de manera concluyente que la violencia perpetrada contra el cónyuge se ha infligido directamente para obligarlo a prestar el consentimiento matrimonial». 
acerca de la nulidad del consentimiento expresado. Si se tiene en cuenta que las exigencias son cumulativas, no parece sencillo que se den con frecuencia estos supuestos, ni que sea éste el objetivo de la norma ${ }^{36}$.

Es nuevamente Mons. Bunge quien advierte que «se debe llegar, a través de documentos médicos o científicos incontrovertibles (como por ejemplo, historias clínicas, pericias psiquiátricas, etc.) a una certeza sin sombras de duda acerca de la nulidad del matrimonio, a través de argumentos que llevan a la evidencia de la incapacidad del sujeto por falta del suficiente uso de razón. Sin duda, la prueba mediante documentos médicos, sobre todo pericias psicológicas o psiquiátricas, no es fácilmente incontrovertible, y por esta razón parece más aplicable este ejemplo a causas de nulidad por falta de suficiente uso de razón (canon $1095,1^{\circ}$ ), que a causas por defecto de discreción de juicio (canon $1095,2^{\circ}$ ) o por incapacidad para asumir las obligaciones esenciales del matrimonio (canon 1095, $3^{\circ}$ ), en las que la valoración de la prueba pericial puede ser a veces muy compleja». Como queda patente, el objeto es facilitar la celeridad del proceso cuando se den las condiciones para llegar a la certeza moral, no ampliar los capítulos de nulidad, ni dejar de exigir la prueba adecuada, ni menos aún prescindir de la certeza que requiere el juez para dictar sentencia. La observancia de estas exigencias, o su deformación o incumplimiento, constituirán la clave para que las normas puedan lograr el objetivo perseguido.

\section{REFLEXIONES FINALES: MIEDOS Y MEDIOS}

Como ha aparecido repetidamente a lo largo del Simposio, las nuevas normas del M. P. Mitis Iudex, las Reglas de procedimiento para tratar las causas de nulidad de matrimonio y su desarrollo complementario en el Subsidio Aplicativo (enviado por el Decano de la Rota Romana a todos los obispos en enero de 2016), han despertado nuevas esperanzas para llegar de modo más directo, cercano y rápido a los fieles que demandan de los tribunales eclesiásticos una palabra sobre la verdad de su vínculo matrimonial. A la vez, también se han levantado críticas -técnicas, o de fondo- y miedos: con frecuencia unas y otros van unidos. Pero gracias a Dios las críticas van dirigidas a las normas concretas

${ }^{36}$ Presentación del nuevo proceso matrimonial, cit., 19. Un caso particular de índole diversa sería una circunstancia eventual que hubiera producido in actu una grave falta de uso de razón, por ejemplo, por contraer el matrimonio bajo efectos serios de la ingestión de alcohol o drogas. Si tal hecho y grado pudiera demostrarse fehacientemente -lo cual tampoco parece sencillo- estaríamos en un supuesto de los previstos para introducir la causa según el proceso brevior. Pero es poco explicable que un hecho de este tipo no saliera a la luz en el momento del pacto conyugal. 
-y a sus posibles desarrollos en la práctica procesal- y no van contra la Iglesia ni contra el Romano Pontífice, ni tampoco contra los principios y objetivos que han impulsado su creación. Salvo siempre el derecho divino -natural o positivo- las normas en la Iglesia son por su propia naturaleza históricas, variables y llamadas a la adecuación a los tiempos ${ }^{37}$; en este sentido, es lógico que estén sujetas a la posibilidad de opiniones diversas: sin ellas no habría habido evolución alguna; sin ellas, no hubiera existido una doctrina canónica ni una jurisprudencia prudente; sin ellas, las normas anteriores jamás hubieran variado.

En definitiva, las críticas tendrán cada una el valor que ofrezcan los argumentos que proponen y su fundamentación ganará peso en la medida en que sea más patente la objetividad necesaria para no juzgar intenciones. Siempre es legítima la crítica a las normas o las sugerencias, también de iure condendo, si existe el respeto necesario. La temporalidad de las normas -en este caso concreto- viene subrayada por su propia naturaleza, que no se encuentra en el propio cuerpo codicial y que atañe a aspectos procedimentales. Lo que pide la Iglesia no es el silencio de los especialistas, sino la obediencia cristiana a lo que está normado -independientemente de la opinión propia-y el deseo eficaz de colaborar en la tarea común, que nos compete a todos.

Si las críticas son explicables -¿qué nueva norma de cierto calado no las recibe?- también el miedo de buena parte de la doctrina canónica y de los operadores de justicia puede comprenderse. Lo que se teme son las consecuencias que pueda tener la aplicación de las nuevas normas ${ }^{38}$ : especialmente que se produzca de hecho una menor protección del carácter personal y permanente del vínculo conyugal; que la celeridad del proceso se confunda con la precipitación; que los supuestos del artículo 14 se apliquen en la práctica como si fueran en sí causas de nulidad; que la declaración de las partes adquiera un pro-

${ }^{37}$ Sobre las sugerencias de iure condendo anteriores al M. P. Dominus Iesus, especialmente las que surgieron en el Sínodo Extraordinario de 2014, vid. M. ROCA FERNÁNDEZ, La reforma del proceso canónico de las causas de nulidad matrimonial: de las propuestas previas a la nueva regulación, Revista General de Derecho Canónico y Derecho Eclesiástico del Estado 40 (2016) en http://www.iustel.com; y cfr. P. Moneta, Processo di nullità, matrimonio e famiglia nell'attuale dibattito sinodale, Stato, Chiese e pluralismo confessionale, http://www.statoechiese.it, 8/2015 (9-III-2015), especialmente 3-6 (consulta 18-XI-2016).

38 Cfr. G. BonI, La recente riforma del processo di nullità matrimoniali. Problemi, criticità, dubbi (3 partes), Stato, Chiese e pluralismo confessionale. Rivista telematica (http://www.statoechiese.it, 10/2016 [14-III-2016], parte 2a $2^{a}$ 17-19 y la bibliografía allí citada [consulta 5-XI-2016]). Vid. también R. RODRÍGUEZ CHACÓN, Antecedentes, estructura y valor jurídico en el sistema normativo canónico de los dos «motu proprio» de 15 agosto de 2015 y sus normas anejas, en M. OLMOS ORTEGA (ed.), Procesos de nulidad tras la reforma del papa Francisco, Dykinson, Madrid 2016, 17-62. 
tagonismo desmedido como prueba dejando -por la vía de hecho- la causa en sus manos; que se debilite la exigencia de una auténtica prueba plena y que se descuide o desvanezca la certeza moral a la que debe llegar el juez.

Por otra parte, existe miedo también a cómo puedan aplicarse las nuevas normas por parte del obispo; al trabajo que pueda sobrevenir especialmente a los vicarios judiciales -no sin particular fundamento-; a los cambios organizativos que puedan ocurrir en cada diócesis; a tener que desempeñar una función -como asesor, o como juez, etc.- sin considerarse con la preparación debida; a la falta de tiempo y de medios materiales... Y los obispos en general -y con razón- tienen miedo al proceso más breve y a la nueva responsabilidad que les atribuye directamente y sin paliativos el $\mathrm{MI}^{39}$.

En efecto, las nuevas normas tienen una finalidad pastoral en relación con la acción de la Iglesia respecto a sus fieles y a sus situaciones matrimoniales y familiares. Y el primer principio e intención para un mayor acercamiento es la responsabilidad directa de los obispos... pero no sólo -ni siquiera principalmente- en el proceso brevior ${ }^{40}$.

Frente a los miedos, tenemos la opción de usar adecuadamente los medios: los nuevos medios que ofrece la norma y los que se proyecten para atender adecuadamente a las necesidades pastorales de las familias. El obispo deberá implicarse de modo directo en la constitución de su tribunal y en la preparación de personal adecuado para crear los organismos de atención pastoral a los que se re-

${ }^{39}$ Sobre el papel del obispo en este proceso brevior, puede verse, entre otros, J. LLOBELL, El ejercicio personal de la potestad judicial del obispo diocesano. Algunas consideraciones preliminares al M. P. «Mitis Iudex» y al M. P. «Mitis et Misericors», Revista General de Derecho Canónico y Eclesiástico del Estado 41 (2016) en http://www.iustel.com, especialmente 20-21; IDEM, Alcune questioni comuni ai tre processi per la dichiarazione di nullità del matrimonio previsti dal M. P. «Mitis Iudex», Ius Ecclesiae 28 (2016) 13-38, especialmente 19-27; J. FERRER ORTIZ, Valoración de las circunstancias que pueden dar lugar al proceso abreviado, Ius Canonicum 56 (2016) 157-192, especialmente 161-169.

40 «Uno de los aspectos más reseñables del M. P. Mitis Iudex es haber colocado al Obispo en el vértice de la función judicial en materia de nulidad del matrimonio -el término que más se repite es "obispo", hasta un total de 35 veces-, encomendándole tareas que, en términos generales, van desde el control y la vigilancia de la administración de justicia, hasta procurar la formación de los operadores jurídicos, pasando por el propio desempeño personal de la función como juez» (C. M. Morán Bustos, El proceso «brevior» ante el obispo diocesano: requisitos procesales y sustantivos de un proceso que ha de ser extraordinario, Revista General de Derecho Canónico y Eclesiástico del Estado 41 [2016] 7 en http://www.iustel.com). Otros muchos autores señalan esta centralidad de la revalorización de la acción personal del obispo en el ámbito judicial; entre ellos, C. PEÑA apunta que la reforma plantea «reforzar la implicación del obispo diocesano en la misión de juzgar, recordando su condición de primer juez de la diócesis, y potenciar la dimensión pastoral del proceso canónico de nulidad» (La reforma de los procesos canónicos de nulidad matrimonial: el m. p. «Mitis Iudex Dominus Iesus», Estudios Eclesiásticos 90 [2015] 629). 
fiere la Exhortación apostólica Amoris Laetitia y la Carta Apostólica Mitis Iudex. Deberá juzgar verdaderamente en los casos que se presenten en el proceso brevior, porque a él le corresponde alcanzar o no la certeza debida y dictar sentencia: pero así como en la redacción de la sentencia -que es suya- puede recibir ayuda de otro, a la hora de plantearse la certeza moral no la puede tomar prestada, ni puede firmar la de otro: es una decisión que apela directamente a su conciencia de cristiano y a su responsabilidad como pastor. También deberá estar enterado de la marcha de su tribunal y de los organismos diocesanos pertinentes, y atender a sus necesidades materiales así como a la formación permanente de sus miembros. E igualmente tendrá que plantearse cómo lograr la financiación de la actividad judicial sin detrimento de la profesionalidad y dedicación de los operadores de la justicia y sin cobrar a las partes los costes debidos ${ }^{41}$. Con todo, el mayor reto que plantea tanto la Amoris laetitia como el Mitis Iudex probablemente es la tarea formativa para implicar a personas competentes y en suficiente número: sacerdotes, religiosas y religiosos, mujeres y varones laicos.

Recordemos, una vez más, que las normas del artículo 14 de las RP no son nuevas puertas a más nulidades, sino ayudas a la celeridad cuando ésta sea posible. No constituyen capítulos de nulidad, sino ejemplos de casos con las condiciones necesarias para el acceso a un proceso más breve que el ordinario, en cuestiones referidas al consentimiento matrimonial. En concreto, si el proceso brevior se utiliza adecuadamente y se consideran atentamente sus exigencias previas, ni será tan fácil que haya muchísimas causas, ni será tan difícil -cuando se presente alguna- juzgar si el supuesto y la documentación presentada es verdaderamente apta para ese tipo de proceso $^{42}$. Por otro lado, no es vano tener en cuenta que el pasar un proceso del procedimiento brevior al ordinario no significa desdoro alguno ni fracaso en el ministerio de juez o de pastor. Ni siquiera significa una negación a la petición de la demanda, porque

${ }^{41}$ Conviene aquí recordar la interesante precisión de M. J. ARROBa CONDE: «No puede pues interpretarse la disposición de RP art. 8, que se refiere a cursos de formación permanente organizados por las diócesis y por la sede apostólica, como una estrategia alternativa a la formación inicial exigida a los miembros del tribunal; dicha formación se imparte sólo en las facultades de derecho canónico». (La experiencia sinodal y la reciente reforma procesal en el Motu Proprio Mitis Iudex Dominus Iesus, Anuario de Derecho Canónico 5 Supl. [Oct 2016] 181, nota 41).

42 «De todas formas, quizás convenga prevenir sobre un intento de uso excesivo, o más bien "a toda costa", de este tipo de proceso por parte de los abogados, que deberán llevar a cabo la necesaria ponderación en la materia, tomando en consideración que el derecho al proceso no habrá nunca de ir en detrimento de la verosimilitud o principio de prueba acerca de la causa o causas en virtud de las que se pueda, en definitiva, declarar la nulidad» (M. Alenda Salinas, ¿¿Nuevas..., cit., 2). 
nunca llega a haber sentencia negativa; se trata simplemente de la constatación de que esa causa exige ulteriores investigaciones y pruebas que son propias de un proceso más detenido: el ordinario.

Quizá lo más relevante en este proceso brevior no serán las sentencias de los obispos, sino el criterio que se vaya haciendo praxis en la admisión de las causas a esta vía expeditiva. Más que en el final de los procesos breviores, la cuestión principal está en su principio, en la aplicación de las vías de acceso. No podemos olvidar que el objetivo de celeridad va unido al objetivo del acompañamiento pastoral, que sin duda será clave a lo largo de todas las vicisitudes, antes, durante y después del proceso, sea este brevior u ordinario. $\mathrm{Y}$ conviene también recordar toda la responsabilidad de cada uno de los miembros de la Iglesia en la tarea de ayudar a los demás y de mostrar a la humanidad cómo se vive en plenitud la realidad matrimonial y familiar. Alentar y construir en positivo será siempre la primera tarea de todo fiel: sin ceder a la hora de manifestar y difundir la plenitud de la verdad, pero procurando hacer fácil a todos su acercamiento gradual a ella a través del trato fraterno que nutre la caridad. Ahí está el ideal y ahí debe estar el optimismo. Y en nuestras manos está convertir las posibles dificultades en verdaderas oportunidades.

Con palabras del papa Francisco: «Para evitar cualquier interpretación desviada, recuerdo que de ninguna manera la Iglesia debe renunciar a proponer el ideal pleno del matrimonio, el proyecto de Dios en toda su grandeza: "Es preciso alentar a los jóvenes bautizados a no dudar ante la riqueza que el sacramento del matrimonio procura a sus proyectos de amor, con la fuerza del sostén que reciben de la gracia de Cristo y de la posibilidad de participar plenamente en la vida de la Iglesia (Relatio synodi 2014, 26)". La tibieza, cualquier forma de relativismo, o un excesivo respeto a la hora de proponerlo, serían una falta de fidelidad al Evangelio y también una falta de amor de la Iglesia hacia los mismos jóvenes. Comprender las situaciones excepcionales nunca implica ocultar la luz del ideal más pleno ni proponer menos que lo que Jesús ofrece al ser humano. Hoy, más importante que una pastoral de los fracasos es el esfuerzo pastoral para consolidar los matrimonios y así prevenir las rupturas (Exh. Ap. Amoris Laetitia, 307)».

En efecto, el desarrollo pleno de la vida matrimonial y familiar será la mejor manifestación y muestra del matrimonio como estructura de la persona en su dimensión sexuada, de la familia como estructura de la sociedad civil y eclesial, y de la realidad conyugal y familiar como el más amplio camino de santidad a través del cual Dios llama a la santidad a la mayor parte de sus hijos. 


\section{Bibliografía}

Alenda Salinas, M., ¿Nuevas causas de nulidad matrimonial canónica? El sentido del art. 14, 1 de las Reglas de procedimiento contenidas en la Carta Apostólica Mitis Iudex Dominus Iesus, Revista General de Derecho Canónico y Derecho Eclesiástico del Estado 40 (2016) en http://www.iustel.com.

ARroba Conde, M. J., La experiencia sinodal y la reciente reforma procesal en el Motu Proprio Mitis Iudex Dominus Iesus, Anuario de Derecho Canónico 5 Supl. [Oct 2016] 165-191.

BAÑARES, J. I., La relación intelecto-voluntad en el consentimiento matrimonial: notas sobre los cc. 1096-1102 del CIC de 1983, Ius Canonicum 33 (1993) 553-603.

BiAnCHI, P., ¿Cuándo es nulo el matrimonio?, Eunsa, Pamplona 2007.

BONI, G., La recente riforma del processo di nullità matrimoniali. Problemi, criticità, dubbi (3 partes), Stato, Chiese e pluralismo confessionale en http://www. statoechiese.it, 10, 2016 (14-III-2016), parte 2a (consulta 5-XI-2016).

Bunge, A., Presentación del nuevo proceso matrimonial, en la 110 Asamblea Plenaria de la Conferencia Episcopal Argentina (PDF, http://www.awbunge.com.ar/, p. 17), consultado el 20 de octubre de 2016.

CEBRIÁ GARCÍA, M. D., Las circunstancias y hechos orientativos de la nulidad clara del art. 14 del Motu Proprio Mitis Iudex Dominus Iesus, para abrir el proceso breve ante el Obispo, Revista General de Derecho Canónico y Derecho Eclesiástico del Estado 40 (2016) en http://www.iustel.com.

D'Auria, A., Fede e sacramentalità del matrimonio. La prospettiva canonica, Ius Ecclesiae 26 (2014) 511-534.

ERRÁZURIZ M., C. J., Il matrimonio e la famiglia quale bene giuridico ecclesiale: introduzione al diritto matrimoniale canonico, Pontificia Università della Santa Croce, Roma 2016.

FERRER ORTIZ, J., Valoración de las circunstancias que pueden dar lugar al proceso abreviado, Ius Canonicum 56 (2016) 157-192.

FRANCESCHI, H., La riforma e il regime delle nullità matrimoniali, en AA.Vv., La riforma del processo matrimoniale (ad un anno dal M. P. Mitis Iudex Dominus Iesus), Actas del XLVIII Congresso Nazionale di Diritto Canonico (Associazione Canonistica Italiana), Udine 5-8 septiembre 2016, Libreria Editrice Vaticana, Ciudad del Vaticano (en prensa).

FrANCISCO, Discurso a la Rota Romana, 22-I-2016 (//w2.vatican.va/content/ francesco/es/speeches/2016/january/documents/papa-francesco_ 20160122_anno-giudiziario-rota-romana.html). 
—, Exhortación Apostólica Amoris Laetitia, Ciudad del Vaticano 2016.

—, M. P. Mitis Iudex Dominus Iesus (y Reglas de procedimiento), 15-VIII-2015, Ciudad del Vaticano 2015.

—, Rescripto ex Audientia, 8-XII-2015 (L'Osservatore Romano, 12-XII-2015, 8).

GAS AIXENDRI, M., Error determinante de la voluntad (c. 1099 CIC) y simulación (c. 1101 \$ 2 CIC). Criterios de delimitación y prueba, con especial referencia a la sacramentalildad del matrimonio, Revista General de Derecho Canónico y Derecho Eclesiástico del Estado 18 (2008) en http://www.iustel.com.

-, La exclusión del bonum fidei y su prueba. Doctrina y jurisprudencia, Ius Canonicum 51 (2011) 207-234.

GUZMÁn PÉREZ, C., La exclusión del bonum prolis en la reciente jurisprudencia de la Rota Romana, en J. Bosch (ed.), Cuestiones actuales de Derecho Canónico y Derecho Eclesiástico del Estado: Actas de las XXXIV Fornadas de Actualidad Canónica, organizadas por la Asociación Española de Canonistas en Madrid, 2325 de abril de 2014, Dykinson, Madrid 2015, 127-179.

Heredia, F., El proceso más breve ante el Obispo, Anuario de Derecho Canónico 5 Supl. [Octubre 2016] 97-122.

Hervada, J., Una Caro. Escritos sobre el matrimonio, Eunsa, Pamplona 2000.

Hervada, J. - Lombardía, P., El Derecho del Pueblo de Dios. Hacia un sistema de Derecho Canónico, vol. III, Derecho Matrimonial (1), Eunsa, Pamplona 1973.

Ladaria, F. L., Presentación del M. P. «Mitis Iudex Dominus Fesus» (15-VIII2015), realizada el 8-IX-2015 (texto accesible en vatican.va).

Llobell, J., El ejercicio personal de la potestad judicial del obispo diocesano. Algunas consideraciones preliminares al M. P. «Mitis Iudex» y al M. P. «Mitis et Misericors», Revista General de Derecho Canónico y Eclesiástico del Estado 41 (2016) en http://www.iustel.com.

-, Alcune questioni comuni ai tre processi per la dichiarazione di nullità del matrimonio previsti dal M. P. «Mitis Iudex», Ius Ecclesiae 28 (2016) 13-38.

MAJER, P., El error que determina la voluntad (can. 1099 del CIC de 1983), Eunsa, Pamplona 1997.

Moneta, P., Processo di nullità, matrimonio e famiglia nell'attuale dibattito sinodale, Stato, Chiese e pluralismo confessionale, http://www.statoechiese.it 8 2015 (9-III-2015) (consulta 18-XI-2016).

—, La dinamica processuale nel m. p. «Mitis Iudex», Ius Ecclesiae 28, 1 (2016) 39-62.

Coram Monier, Sententia 18 februarii 2000, R. R. Dec., vol. XCII, 185-194. 
Morán Bustos, C. M., El proceso «brevior» ante el obispo diocesano: requisitos procesales y sustantivos de un proceso que ba de ser extraordinario, Revista General de Derecho Canónico y Eclesiástico del Estado 41 (2016) en http: //www.iustel.com.

-, Retos de la reforma procesal de la nulidad del matrimonio, Ius Canonicum 56 (2016) 9-40.

Moreno Ramírez, D., Relevancia de la sacramentalidad del matrimonio en relación con la nulidad del consentimiento, Universidad San Dámaso, Madrid 2014.

NIEVA, J. A., El bautizado que contrae matrimonio sin fe no necesariamente excluye el consentimiento matrimonial, Ius Canonicum 54 (2014) 521-565.

NúÑEZ, G., El proceso brevior: exigencias y estructura, Ius Canonicum 56 (2016) 135-155.

Ortiz, M. A., Fe y matrimonio, en J. Bosch (ed.), Cuestiones actuales de Derecho Canónico y Derecho Eclesiástico del Estado: Actas de las XXXIV Fornadas de Actualidad Canónica, organizadas por la Asociación Española de Canonistas en Madrid, 23-25 de abril de 2014, Dykinson, Madrid 2015, 266-292.

PEÑA, C., La reforma de los procesos canónicos de nulidad matrimonial: el m. p. «Mitis Iudex Dominus Iesus», Estudios Eclesiásticos 90 (2015) 621-682.

Pompedda, M. F., Mancanza di fede e consenso matrimoniale, Studi di Diritto Matrimoniale Canonico, vol. I, Giuffrè, Milano 1993, 399-450.

RINCÓN PÉREZ, T., La exclusión de la sacramentalidad del matrimonio. ¿Son convincentes las razones que inspiran el incipiente cambio jurisprudencial?, Ius Ecclesiae 6 (1994) 465-487.

- La peculiaridad sacramental del matrimonio y sus consecuencias canónicas (Comentario a las Alocuciones del Papa a la Rota Romana de 2001 y 2003), Ius Canonicum 44 (2004) 281-307.

Roca Fernández, M., La reforma del proceso canónico de las causas de nulidad matrimonial: de las propuestas previas a la nueva regulación, Revista General de Derecho Canónico y Derecho Eclesiástico del Estado 40 (2016) en http://www.iustel.com.

Rodríguez Chacón, R., Antecedentes, estructura y valor jurídico en el sistema normativo canónico de los dos «motu proprio» de 15 agosto de 2015 y sus normas anejas, en M. Olmos Ortega (ed.), Procesos de nulidad tras la reforma del papa Francisco, Dykinson, Madrid 2016, 17-62.

Schöch, N., Presentación del M. P. «Mitis Iudex Dominus fesus» (15-VIII2015), realizada el 8-IX-2015 (texto accesible en vatican.va).

Coram STAFFa Sententia, 29-XI-1975, Periodica 66 (1977) 297-325. 
Coram STANKIEwICZ Sententia, 26 ianuarii 2001, R. R. Dec., vol. XCIII, 92104.

Tribunal Apostólico de la Rota Romana, Subsidio Aplicativo del M. P. Mitis Iudex Dominus Iesus, Ciudad del Vaticano 2016.

Vega GutiéRrez, A. M., La exclusión de elementos esenciales y propiedades del matrimonio, en P.-J. VILADRICH - J. ESCRIVÁ - J. I. BAÑARES - J. MiRAS (dirs.), Matrimonio. El Matrimonio y su expresión canónica ante el III Milenio, Instituto de Ciencias para la Familia, Eunsa, Pamplona 2000, 1219-1265.

VILADRICH, P.-J., El consentimiento matrimonial, Eunsa, Pamplona 1998. 
